\title{
An unusual form of coloniic atresia diagnosed in infant of 8months
}

\begin{abstract}
Purpose: Colonic localization is the rarest form of Intestinal atresia. Diagnosis is usually made in the neonatal period by an occlusive syndrome. We report a case diagnosed in Abidjan, in a table of chronic constipation in an infant 8 months also having macroglossia.

Case report: A 8months-old male Infant was admitted in an array of chronic constipation, bloated stomach with few food vomiting evolving since the age of four (04)months. Physical examination noted a sub-occlusive syndrome associated with upper digestive tract malformation. There was no anal imperforation and anorectal stimulation was not accompanied with stool emission. Suspecting the coexistence of an abnormality of the lower digestive tract, We carried out a low digestive opacification that objectived a long and small pertuis of third proximal transverse colon through which the contrast product passes, associated with a dilation of the colon segment upstream of the lesion and a smaller downstream colon. During evacuation, a stop image is noted in a concave cup downstream of the contrast product. There was no abnormal length of colon. We recommended surgery. The patient, for lack of financial means, was lost sight of.
\end{abstract}

Conclusion: We presented a case of atresia we see as type I according to the classification of LOUW. However, unusual features related to age at diagnosis, clinical manifestations, associated malformations and radiographic images obtained with barium enema are noted.

Keywords: colonic, diagnosis, radiographic, barium enema, syndrome
Volume 4 Issue 2 - 2017

\author{
Anhum Konan, Idrissa Garba, Olivier Tra \\ bi,Alionou Schécheou, Abdoulaye Touré, \\ Ali Coulibaly, N'goranKouamé, Anne- \\ marieN'goan-Domoua \\ Department of Radiology, Yopougon University hospital, Côte \\ d'lvoire
}

Correspondence: Anhum Konan, Department of Radiology, Yopougon University hospital,Abidjan, Côte d'Ivoire, Email anhum_konan@yahoo.fr

Received: July 31, 2017 | Published: August 28, 2017

\section{Introduction}

Intestinal atresia is a congenital, hereditary or acquired disease. Colonic localization is the rarest form. The diagnosis is usually made in the neonatal period by an occlusive syndrome. ${ }^{1}$ We report a case diagnosed in Abidjan, in a table of chronic constipation in an infant 8 months also having macroglossia.

\section{Observation}

A 8month-old male Infant, from Ivory Coast, born out of a nonconsanguineous marriage, 2 nd of a sibling of 2 children with an elder brother of 3years without anomaly. He is from a non-follow-up pregnancy. He admitted in an array of chronic constipation, bloated stomach with few foods vomiting evolving since the age of four (04) months. There was no bilious vomiting or stoppage of matter and gases. Parents testified there was a delay in the emission of meconium at the 48th hour. Physical examination showed an infant presenting slender limbs, weighing $8 \mathrm{Kg}$ with general condition little altered (no delay in weight or psychomotor), macroglossia present since birth (Figure 1), unstressed umbilical hernia (Figure 2) with a small hernial sac, no malformation of the nervous system or bone skeleton, abdomen supple and depressible, distended with diffuse tympanism, without collateral venous circulation, mass and defense. There was no anal imperforation and anorectal stimulation was not accompanied with stool emission.

In total, it is a sub-occlusive syndrom associated with upper digestive tract malformation. We suspect the coexistence of an abnormality of the lower digestive tract. It evoked, the less likely the most likely, a irritable bowel syndrom, a gastrointestinal stenosis and Hirschsprung disease. We then carried out the following additional tests: Thorax and abdomen radiological examination without preparation showed (Figure 3): a large aeric and stercoral stasis drawing the entire colon, including the rectum, an absence of hydro-aerial level, a thickening of the intestinal walls of the recto-sigmoid region.

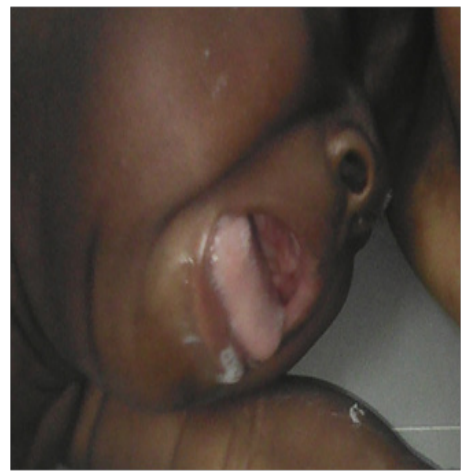

Figure I Macroglossia.

Ultrasound, abdominal and transfontanellar, greatly hampered by intestinal gas distension and the impossible cooperation of the infant patient noted the absence of liquid stomach stasis, pyloric olive, compressive pathological mass, abnormalities of the full urodigestive organs. Ventricular system, cerebral parenchyma and pericerebral spaces were without abnormality. 


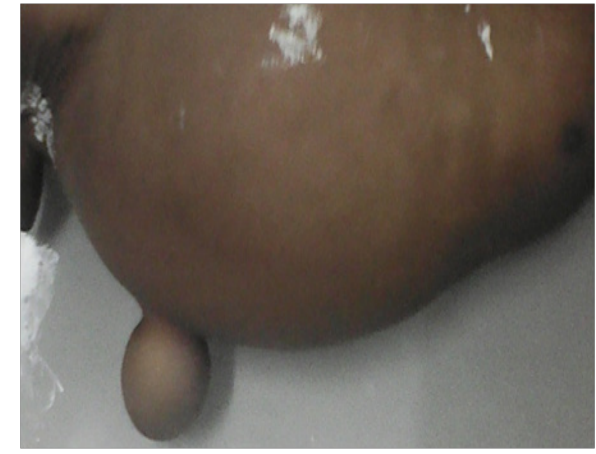

Figure 2 Umbilical hernia.

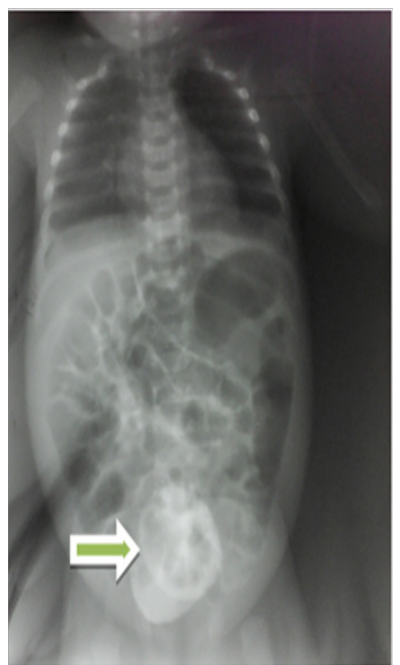

Figure 3 Thoraco abdominal radiological examination without preparation: significant aeric and stercoral stasis drawing the whole colonic frame (including rectum) without hydro-aerial level. Thickening of the colonic wall rectosigmoid region (green arrow).

Low digestive opacification objectived a long and small pertuis of third proximal transverse colon through which the contrast product passes associated with a dilation of the colon segment upstream of the lesion and a smaller downstream colon (Figure 4). During evacuation, occurring 5hours after the beginning of the examination, a stop image is noted in a concave cup downstream of the contrast product (Figure 5). We noted presence of colonic austration in the recto-sigmoid region and no abnormal length of colon.

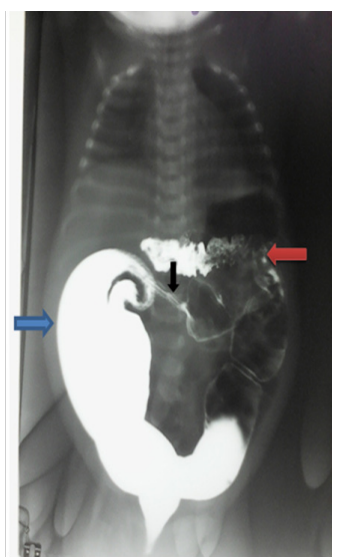

Figure 4 Barium enema showing transverse colon atresia segment (black arrow), the dilated upstream colon (blue arrow) and the downstream colon of reduced size (red arrow).
Biologic infectious assessment is negative (C-reactive protein $=6 \mathrm{mg} / \mathrm{l}$ and a normal leucocyte count at 7,500 cells $/ \mathrm{ml}$ ). We recommended surgery. The patient, for lack of financial means, was lost sight of.

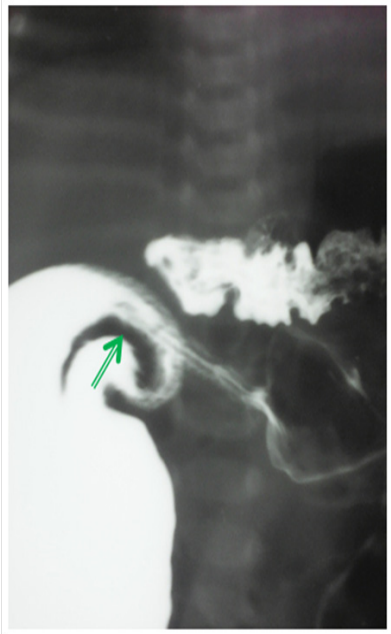

Figure 5 "Wind-sock" sign, image of stop in concave cup downstream during evacuation (green arrow).

\section{Discussion}

Diagnosis of irritable bowel syndrome was eliminated in presence of an anatomical lesion of transverse colon, objectified with barium enema. Digestive stenosis, in particular pyloric stenosis, is not retained either in the general condition of the infant, the absence of fracture of the weight curve, postprandial vomiting and pyloric olive on ultrasound. The absence of a transition zone, that means a short zone of progressive dilation, between the dilated upstream colon and the smaller downstream colon, the presence of air at the rectum and 1 the negative probe test also refuted the most likely diagnosis of Hirschsprung disease.

two orders of arguments, considered as pathognomonic of type I colic atresia were noted : Presence of a long and small pertuis of third proximal transverse colon through which the contrast product passes associated with dilation of the colon segment upstream of the lesion and a downstream colon of smaller size. These images correspond to the type I of the colonic atresia according to LOUW that is defined by a complete mucous diaphragm obstructing the intestinal lumen, without interrupting sero-muscular and externally by a disparity of caliber. The second sign is an image of stop in concave cup downstream of contrast product, during evacuation corresponding to the "Windsock" sign described by BLANK and collaborators. ${ }^{2}$

However, this case of atresia presents clinical and radiological originalities: Our case reports a case of colonic atresia diagnosed in an 8month-old infant, long after the neonatal period (0-28days), which is found in R. Saouab, Watts and Barlas ETENSEL studies. They demonstrate symptoms beginning in the days following birth with an average of 01 to 04 days and extremes of 03 hours to 05 days. ${ }^{1,3-7}$ Would not there be, in the case observed, a latency period between the birth and the beginning of the signs, as is the case for other digestive congenital pathologies, like hypertrophic stenosis of pylorus?

The reason for consultation is chronic constipation with a few dietary vomiting. The patient emits rare gas and hard saddle once a week. The abdomen is distended. There was no obvious sign of intestinal occlusion (no bilious vomiting or stoppage of matter and 
gas). In studies conducted in Africa by El OUACHEKRADI and F. BARGI and in Europe by WATTS, BARLAS ETENSEL and other, cases of colonic atresia proved by intestinal obstruction regardless of the type..$^{1,3-5,7,8}$

Type I of colonic atresia, generally observed, present a mucosal diaphragm, realizing the colonic obstruction. The lack of stopping materials and gas, in our case, could come from the existence of a relatively large hole through the mucous diaphragm. Thus, we can understand the lack of overt signs of bowel obstruction and the occurrence of the symptoms at the age of weaning, that is to say, a passage exclusively liquid diet to a solid diet and/Or semi-liquid; the saddles becoming more and more compact and thick.

Physical examination objective a macroglossia, present since birth. Tongue seems not to fit in the oral cavity. It overflows and prevents total occlusion of the mouth. There is also an unthrottled umbilical hernia with a little hernial sac. We did not find megacolon and small bowel atresia. According to LOUW, ${ }^{5,9-12}$ in our case it is an interruption of the superior mesenteric vascular flow, intended for the irrigation of the small bowel and the proximal half of the colon, which would be the cause of atresia. The associated anomalies are expected to be small bowel atresia and a megacolon that we do not find. ${ }^{5,13-15}$ We observe macroglossia and umbilical hernia. Our case would therefore be part of a diffuse polymalformative syndrome.

This is a colonic atresia classified as type I of LOUW, with an atrestic segment located at the transverse colon proximal third. Usually, the seat of colonic atresia of this type is the distal half of the colon, particularly the region under the left colonic angle, vascularized by the inferior mesenteric artery. ${ }^{5,7}$ This location is rarely described.

The frontal thoracoabdominal radiography without preparation showed a regular thickening of the recto-sigmoidal walls in favor of a rectocolitis. It could be a recto-colitis of ischemic origin, that is to say an identical etiology to that of atresia.

\section{Conclusion}

We presented a case of atresia we see as type I according to the classification of LOUW. However, unusual features related to age at diagnosis, clinical manifestations, associated malformations and radiographic images obtained with barium enema are noted.

\section{Acknowledgements}

None.

\section{Conflict of interest}

Author declares that there is no conflict of interest.

\section{References}

1. Saouab R, Mrani Alaoui N, Ettaibi F, et al. Cause rare d'occlusion intestinale néonatale: l'atrésie tiscolique. Feuillets de Radiologie. 2009;49(3):187-192.

2. Hélardot P, Bienaymé J, Bargy F. Chirurgie digestive de l'enfant. doin éditeurs - Paris. 1998.

3. El Ouachekradi Abdellah. Atrésie colique à propos de 3 cas. These $\mathrm{N}^{\circ} 122 / 12$ universite sidi mohammed ben abdellah. Faculte de medecine et de pharmacie-FES. 2012:31-75.

4. Watts AC, Sabharwal AJ, Mackinlay GA, et al. Congenital colonic atresia: should primary anastomosis always be the goal? Pediatr Surg Int 2003;19(1-2):14-17.

5. Barlas Etensel, Gunyuz Temir, Aytac Karkiner, et al. Atresia of the colon. Journal of Pediatric Surgery. 2005;40(8):1258-1258.

6. Alessandro Calisti, Claudio olivieri, Riccardo Coletta. Jejunoileal atresia: Factors affecting the outcome and long terme squelea. J Clin Neonato. $2012 ; 1(1): 38-41$.

7. Karnak I, Ciftci AO, Senocak ME, et al. Colonic atresia: surgical management and outcome. Pediatr Surg Int. 2001;17(8):631-635.

8. Bargy F, Beaudoin S. Urgences chirurgicales du nouveau-né et du nourrisson. Surgical emergencies in neonates and infants. 2006;4-002-S-75.

9. Cox SC, Numanoglu A, Millar AJW, et al. Colonic atresia: spectrum of presentation and pitfalls in management. A review of 14 cases. Pediatr Surg Int. 2005;21(10):813-818.

10. Vicki Martin, Charles Shaw-Smith. Review of genetic factors in intestinal malrotation. Pediatr Surg Int. 2010;26(8):769-781.

11. Haroon Mansoor, Naila Kanwal, Mahmood Shaukat. Atresia of the Ascending Colon: A. APSP J Case Rep. 2010;1(1):3.

12. Charieg. Cause rare d'occlusion néonatale : atrésie colique. A propos de 3 cas. Archives de pédiatrie. 2008;15:887-922.

13. Chieh-Teng H, Shie-Shan W, Jia-Fu H, et al. Congenital Colonic Atresia: Report of One Case. Pediatr Neonatol. 2009;51(3):186-189.

14. Kasbi NA, Bellagha I, Hammou A. Occlusion néonatale, apport de l'imagerie. Journal de pédiatrie et de puériculture. 2004;17(2):112-119.

15. Takongmo S, Binam F, Monebenimp F, et al. Les occlusions néonatales dans un service de chirurgie générale à Yaoundé (Cameroun). Méd Afrique noire. 2000;47(3):153-156. 